Socioeconomic Status and Equivalency Sports

The Journal of SPORT, 2020, 8(1), 4-22

(C) Kent State University

\title{
Does Socioeconomic Status Limit an Equivalency Sport Coach's Ability to Recruit Student-Athletes
}

\author{
Daniel Ballou \\ Central Michigan University \\ Jen Sieszputowski \\ Central Michigan University \\ Kristen Knutson \\ Central Michigan University
}




\begin{abstract}
The purpose of this exploratory, quantitative study was to determine whether NCAA Division I coaches in equivalency sports, where scholarships are divided among athletes, consider a potential recruit's socioeconomic status prior to and during the recruiting process. A survey was sent to all NCAA Division I soccer, track \& field, baseball, and softball head coaches. Surveys were returned at a rate of 24.6 percent. The data sets were analyzed through mean comparisons and ANOVA analyses. The results of this study indicated that socioeconomic status is a factor in the recruiting process. Additionally, the data revealed that involvement in club sport activity is a primary recruiting tool that can restrict potential recruits from lower socioeconomic households. Collegiate coaches and administrators, as well as high school coaches, can utilize the findings to help learn more about other funding opportunities, including those related to academic standing and community service.
\end{abstract}

\title{
Introduction
}

The benefits of a college degree have been found to extend beyond individuals, to society as a whole (Ma, Pender, \& Welch, 2016). Research has shown low-income students face barriers to college success from elementary all the way through post-secondary education (United States, 2014). The high cost associated with attending college can leave higher educational attainment out of reach for many. Student-athletes from families with low socioeconomic status (SES) are not immune to educational attainment inequality, yet little research exists that informs about the role SES plays during the sport recruiting process. The purpose of this study was twofold: (a) to explore if NCAA Division I equivalency sport coaches consider a potential recruit's SES in the recruiting process and (b) to examine if not participating in club sports limits the opportunity of being recruited. The following research questions (RQ) were devised:

RQ1: How much does a potential recruit's SES impact the recruiting process at NCAA Football Bowl Subdivision (FBS) schools?

RQ2: Does non-participation in club sports limit the opportunity of being recruited in equivalency sports at FBS-member schools?

Sports deemed equivalency status are those that are able to offer partial scholarships to potential student-athletes (NCAA, 2019). For example, NCAA Division I college baseball is allowed the equivalence of 11.7 scholarships, but the typical roster size is roughly $32-35$ players. With that, a student-athlete may receive a scholarship that would cover books each semester, and that may equate 
to a $10 \%$ scholarship (for example) so the remaining $90 \%$ of that scholarship could also be divided among one or more student-athletes in the same manner. These are opposed to what the NCAA considers "headcount" sports (such as football, men's and women's basketball), where each student-athlete is provided a full grant in aid (NCAA, 2019).

The null hypothesis is that there is no difference in how equivalency sport coaches in six sports recruit related to a potential recruit's SES status. The alternative hypothesis is that there is a difference in how equivalency sport coaches in six sports recruit related to a potential recruit's SES status.

\section{Literature Review}

Over the past 40 years, the number of jobs requiring postsecondary education has doubled (Carnevale, Smith \& Strohl, 2010). Education and training beyond a high school diploma is now required for three-quarters of the fastest growing occupations (U.S. Department of Education, n.d.). The U.S. Department of Education (n.d.) announced that a college degree is "no longer a luxury for the privileged few, but a necessity for individual economic opportunity and America's competitiveness in the global economy" (para. 2). The benefits of earning a college degree extend beyond economic opportunities. Higher levels of education have been associated with fewer health risk behaviors, including increased exercise and decreased smoking rates, along with social and psychological resources like greater sense of control and more social support (Ross \& Wu, 1995). Postsecondary education has also been found to make people more goaloriented and better decision makers about marriage and parenting (Oreopoulis \& Salvanes, 2011).

Although a college education is considered more important than ever before, large gaps remain in educational achievement between low-income students and their higher-income peers (United States, 2014). Half of all highincome families earn a bachelor's degree by age 25 , while only about $10 \%$ of people from low-income families attain that level (Bailey \& Dynarski, 2011). A college education has been recognized as critical for social mobility and one of the surest ways for low-income families to move into the middle class (United States, 2014, para 1). Research shows when someone is born into the bottom fifth of the income distribution earns a college degree, their chance of making it out of the bottom increases by $50 \%$, and their chance of making it to the top nearly quadruple (Isaacs, Sawhil, \& Haskins, 2008).

The financial barrier of attending college is a steep one due to rising tuition costs. According to the National Center for Educational Statistics (2017), the average cost of undergraduate tuition, fees, room, and board at public institutions rose 34\% between the years of 2005-06 and 2015-16. During the 
2016-2017 academic year undergraduate state residents paid an average of $\$ 19,488$ for tuition, fees, room, and board to attend public 4-year institutions. Out-of-state students (the NCES does not differentiate between out-of-state students versus international students) paid an average of $\$ 24,854$ for tuition and fees alone. During that same year, the average cost of tuition, fees, room, and board at private 4 -year colleges was $\$ 41,468$, with $\$ 29,478$ going toward tuition and fees (National Center for Education Statistics, 2017, Table 330.20).

Currently, Federal Pell Grants, which are limited to students who show financial need, cover only about $30 \%$ of the cost of a four-year public college education (U.S. Department of Education, n.d.). Without adequate levels of need-based aid, students who have been traditionally underrepresented and underserved by America's colleges and universities have a decreased chance of going to college (Gieser, 2012). Students from low SES backgrounds who are able to attend college still face additional challenges. Terenzini, Cabrera, and Bernal (2001) found that low SES students are less likely to earn a degree from a four-year institution compared to others. Similarly, the National Center for Education Statistics (2017) reported that students from families with low-income, or with parents who did not have a bachelor's degree, were more likely to drop out of college compared to students from families with higher income, or with parents holding bachelor's degrees or higher. Walpole (2003) indicated the financial stress on the lower socioeconomic students results in lower grade point averages and dropping out of the college.

While previous research has identified educational attainment barriers for low-income students (Smith, Pender, \& Howell, 2013; Haskins, Holzer, \& Lerman, 2009) few studies specifically focus on student-athletes with low SES. Huffman and Cooper (2012) looked at the SES of Division I football studentathletes in terms of college choice factors; however, the same financial barriers do not exist for football student-athletes due to football being a headcount (fully funded) sport. Student-athletes in headcount sports have all expenses related to tuition, room and board covered. The sports the authors selected for this study are not fully funded so the allotted number of scholarships are divided among student-athletes. Most team members receive a percentage scholarship that may cover some cost of attendance, but rarely would a scholarship be provided that would fully fund a student-athlete. With that, coaches of these sports may explore more potential funding opportunities through academics and community-based scholarships. This study focuses on the equivalency sports of men's soccer, women's soccer, men's track and field, women's track and field, baseball, and softball. According to the NCAA 2019-20 Division I Manual (2019), the number of scholarships vary for each of the equivalency sports. Men's soccer receives 9.9 scholarships that can be divided among the typical roster size of 30 players. Women's soccer receives 14 scholarships that can be divided among the typical 
roster size of 30 players. Women's and men's track and field each receive 12.6 scholarships that can be divided among the typical roster sizes of 75 and 30 athletes respectively. Baseball receives 11.7 scholarships that can be divided among the typical roster size of 35 players. Softball receives 12 scholarships that can be divided among the typical roster size of 19 players (NCAA, 2019, p. 216). Student-athletes in these sports receive only part of a scholarship (some receive none), or a percentage of a scholarship so they must then find the money to make up the remaining percentage of expenses. This may be nearly impossible for athletes from low socioeconomic backgrounds. This also creates questions related to where coaches can recruit geographically due to out-of-state tuition costs for these sports.

\section{Club Sport Financial Barriers}

Costs associated with club sport and club participation can be a barrier for those who have limited means. Families with low socioeconomic backgrounds may not be able to afford to put their children in club activities. Without the opportunity to participate in club activities, student-athletes may have less exposure and could be eliminated from recruiting processes that focus on club competition. According to Moore (2017), the NCAA surveyed 21,233 current college athletes to determine if they played club sports during their high/middle school years. Athletes in multiple sports overwhelmingly reported that they played on a club team. The survey showed soccer athletes reported $95 \%$ of women and $93 \%$ of men played club soccer; baseball and softball reported $94 \%$ of softball players and $87 \%$ of baseball players competed on club teams; yet only $31 \%$ of men's track and field and $32 \%$ of women's track and field athletes competed on a club track team (Moore, 2017). Smith (2017) explained in soccer, membership dues for club participation can range from about $\$ 2,500$ to $\$ 5,000$ per year. These costs typically cover coaches' salaries, league and referee fees, state and national registration fees, player insurance, and player development programs (Smith, 2017). Smith (2017) also found travel costs, which vary depending on how teams travel, can range from a few hundred to several thousand dollars per year. In softball, team fees, which are usually just over $\$ 1,000$, normally don't include travel and hotel costs. Gear and other equipment can range from $\$ 200$ to $\$ 500$. Lessons are $\$ 75$ per session, which is about $\$ 3,000$ for 40 weeks of training. In club or travel baseball one can spend about $\$ 3,700$ per year. Those costs can easily rise up to $\$ 8,000$ for extra training services and traveling to out-of-state tournaments (Smith, 2017). 
In another study, Post et al. (2018) surveyed 949 parents of club sport youth athletes and found parents spend between \$500-3,000 USD per year on club sport activities for their children. The survey results also showed most parents had a total household income greater than $\$ 100,000$ USD and a bachelor's degree or higher of educational attainment (Post et al., 2018).

\section{Method}

\section{Participants}

This study was conducted at the NCAA Division I level and included all colleges and universities that compete at the Division I level in at least one sport. There are roughly 350 member schools that comprise NCAA Division I, which includes more than 6,000 athletic teams. This includes those leagues deemed "Power 5" conferences: Big 12, Atlantic Coast Conference (ACC), Big Ten, Pac12, and Southeastern Conference (SEC). It also includes conferences that have been coined "The Group of 5": American Athletic, Conference USA, FBS Independents, Mid-American, Mountain West, and Sun Belt. Participants in the study were 331 NCAA Division I men's and women's soccer; men's and women's track and field; baseball and softball head coaches. Participants were recruited through College Coaches Online, a search engine that contains a database of current college and university athletic coaches at NCAA universities (www.collegecoachesonline.com). Thus, the sample was non-random, stratified, and purposive. A total of 1,341 surveys were emailed. Twenty-four of the surveys bounced back as undeliverable. Of the 1,317 successfully emailed surveys, 364 responses were received (response rate of 27.6\%). Thirty-three surveys were excluded from the study due to missing items. Therefore, a final sample of 331 surveys (response rate of 24.6\%) was suitable for analysis.

The demographic information that was gathered from the survey responses indicated that all the participating baseball coaches had a mean age range of 46-51 and the mean years of coaching experience range was 16-20 years. The softball coaches had a mean age range of 46-51 years and their mean coaching experience was 16-20 years. Men's track and field coaches had a mean age range of 51-56 years old and their mean coaching experience was 16-20 years. Women's track and field coaches had a mean age range of 51-56 years with 21-25 years of coaching experience. Men's soccer coaches had a mean age range of 40-45 years and they had 21-25 years of coaching experience. Women's soccer coaches had a mean age range of 46-51 years and 21-25 years of coaching experience. Table 1 shows the number of complete responses for each sport. 
Table 1

Survey Responses by Sport

\begin{tabular}{lc}
\multicolumn{1}{c}{ Sport } & Respondents $(\mathrm{n}=331)$ \\
\hline Baseball & 37 \\
Softball & 55 \\
Track (men) & 61 \\
Track (women) & 67 \\
Soccer (men) & 38 \\
Soccer (women) & 73
\end{tabular}

\section{Questionnaire}

Coaches completed a 15-item online questionnaire that was developed for this project. The first 11 questions were specifically related to recruiting and socioeconomic status. Questions $12-15$ asked for demographic information related to coaching experience and age range. To test for reliability and readability of survey questions, a pilot test was conducted with six Division I head coaches at the researchers' university. Each coach critiqued the questions and provided feedback and suggestions. The content of the questions remained the same, but wording changes were made based on the suggestions. The six coaches were not included in the final study.

\section{Data Collection}

Survey data were collected using online cloud-based survey development software called SurveyMonkey (www.surveymonkey.com). The survey was sent out via email three times. The first time was in May 2017, as the academic year concluded. The second time was in July 2017, and a third time when students were returning to school in September 2017. In October 2017, data were inputted into SPSS (Version 24). The data were analyzed and quantified statistically. Scores were calculated on a Likert scale using the following scoring system:

$$
\begin{aligned}
& 1=\text { strongly disagree } \\
& 2=\text { disagree } \\
& 3=\text { somewhat disagree } \\
& 4=\text { somewhat agree } \\
& 5=\text { agree } \\
& 6=\text { strongly agree }
\end{aligned}
$$


Based on this system, any score that scored a value less than four (4) meant the response had some level of disagreement to the question. Conversely, any score that had a value greater than four (4) meant the response had some level of agreement to the question.

\section{Data Analysis}

After the data were collected and inputted into SPSS, researchers began the analysis. With the quantitative data, the process began with an evaluation of basic central tendencies of the responses. Analyzing the means of the responses stratified between sports provided an average to determine if the coaches generally agreed or disagreed to the question and to what level. After evaluating the mean scores (by sport), those mean scores were compared to one another using independent samples t-tests and factorial ANOVA testing. This was done to compare the means of the male sport responses and the female sport responses. This was of note to determine if male sport coaches agreed that socioeconomic status plays a larger role in recruiting potential student-athletes than female sports because of the varying number of scholarships in the same sports. For example, men's soccer has 9.9 scholarships available while women's soccer has 14 scholarships available.

\section{Results}

The first step in the results process began with an overall look at the 11 individual questions specific to the recruiting process to compare the responses of the coaches by sport. The questions were analyzed one at a time and statistically tested one at a time in order to determine the mean response scores by the coaches of each sport. Of special interest were those questions where coaches of all six sports responded at a consistent level on the question scale. This occurred multiple times and each time it did, coaches were at some level of agreement between the scale level 4 (somewhat agree) and 5 (agree). It should be noted that any time there was no statistical distinction between responses it was because the coaches were all in agreement on a specific question. Further information on these questions is presented through the actual scores located within the tables contained in the narrative.

An independent samples t-test was utilized as the next step in the analysis of the research project in order to compare "like" sports while at the same time comparing the differences between responses of male and female sport coaches (baseball/softball, soccer men/soccer women, track and field men/track and field women). It should be noted that in track and field, some head coaches are the same for both the men and women. With that, coaches were asked to complete a 
survey for each sport. An independent samples t-test was appropriate because it is an inferential statistical test that determines whether there is a statistically significant difference between the means in two unrelated groups (Raymondo, 2015). For this study, the significance threshold was set at .05.

\section{Baseball/Softball}

For the sports of baseball and softball, five of the 11 questions showed statistically significant differences between the coaches of the two sports. This was expected primarily because baseball has a total of 11.7 scholarships to divide among roster sizes typically ranging from 30 - 35 student-athletes, compared to softball, which has 12 scholarships to offer, and roster sizes that typically range from $18-22$ student-athletes. Based on the responses, baseball and softball coaches were statistically significant in five of the 11 questions. Questions 1, 2, 5, 7,10 , and 11 saw little variation in responses, but all six of those questions resulted in mean scores that at least fell in the "somewhat agree" category.

The five questions that showed evidence of statistical significance between baseball and softball coaches were questions 3, 4, 6, 8, and 9. Question 3 directly asked coaches if they had experienced an inability to recruit a potential student-athlete based solely on SES. The mean score for baseball coaches was $4.84(\mathrm{n}=37)$, while softball coaches averaged a response of $3.93(\mathrm{n}=55)$, and $p=.004$. This shows that baseball coaches "agree" that they have been limited in recruiting potential student-athletes from low SES households. While statistically significant, softball coaches fell between "somewhat disagree" and "somewhat agree", but falling much closer to "somewhat agree".

Question 4 from the survey asked coaches if they felt it was difficult to recruit from low SES households due to the equivalency status of their sports. Both sets of coaches felt this was the case, with the baseball coaches mean score of 4.81 , being very close to "agree" in the survey. Softball coaches mean score of 4.15 placed them just above the "somewhat agree" category. While in agreement that recruiting from low SES households is difficult, this question showed statistical significance $(p=.029)$.

Question 6 asked coaches whether their recruiting was impacted by geographical limitations. Baseball coaches felt this was the case, as their mean score fell nearly halfway between "somewhat agree" and "agree" $(\bar{x}=4.46)$. Softball coaches "somewhat disagreed" with this question $(\bar{x}=3.67, p=.019)$.

Question 8 addressed how thoroughly coaches worked with their school's compliance department to exhaust all potential funding sources before determining the percentage of scholarship they were able to offer recruits. While statistically significant, both sets of coaches responded at levels greater than "somewhat agree" (baseball $\bar{x}=4.84$, softball $\bar{x}=4.20 ; p=.039$ ). 
Question 9 dealt with whether coaches felt the equivalency status of their sport was discriminatory toward potential recruits from low SES households. Baseball coaches felt this was the case as their mean score split the categories of "somewhat agree" and "agree" $(\bar{x}=4.51)$. Softball coaches, however, felt this was not the case as evidenced by their score falling in the "somewhat disagree" range $(\bar{x}=3.84)$.

\section{Soccer}

An independent samples t-test was also conducted comparing men's $(n=38)$ and women's $(n=73)$ soccer coaches (the significance threshold was set at .05$)$. From the statistical test, five questions showed statistical significance, while six did not. Compared to the baseball/softball coaches, Q8 was the only question that showed common significance between both like sports. For soccer, questions 1,2,5,8, and 10 were statistically different. The six questions that did not see a significant difference, found that the coaches responded with consistent answers related to overall levels of agreement or disagreement. The only exception to this was Q6, which contained restrictions on recruiting geographically. Men's soccer coaches "somewhat agreed" this was the case $(\bar{x}=4.05)$, while women's coaches "somewhat disagreed" with the question $(\bar{x}=3.68)$. Again, there was no statistical significance to this question even though the coaches differed.

The first statistically significant question between both sets of soccer coaches was Q1 and how much time is spent looking at other funding sources prior to offering an equivalency scholarship to recruits. Men's coaches were greater than "agree" $(\bar{x}=5.21)$, while women's coaches "somewhat agreed" $(\bar{x}=4.58)$. The evidence of statistical significance is supported by $p=.018, \mathrm{HOV}$ $p=.261$ (HOV statistic shown due to the $\mathrm{n}$ differences).

Q2 asked coaches if they determined a potential recruit's SES prior to and during the recruiting process. Men's soccer coaches responded that this determination is significant, as evidenced by the mean score of 4.71, which fell between 'somewhat agree" and "agree", but more near "agree". Women's coaches responded that the determination was not as prominent for them, as shown by a mean score of 3.95, which fell just short of "somewhat agree" ( $p=.006, \mathrm{HOV}$ $p=.480)$.

Q5 addressed whether coaches had seen student-athletes in their sports drop out of school due to financial reasons. Men's coaches "somewhat agreed" with this question, as evidenced by a mean score of 4.32, while women's coaches "somewhat disagreed" as evidenced by their mean score of 3.04. ( $p<.001, \mathrm{HOV}$ $p=.067$ ). 
Q8 was also statistically significant related to how closely the coaches work with their school's compliance department. Men's soccer coaches had a mean score of 4.76, which fell close to "agree". Women's coaches had a mean score of 4.08, or nearly right at the score level of the "somewhat agree" category.

Q11 is related to club sport involvement, and whether coaches recruited from club sports, and if they felt club sports were discriminatory toward low SES households. Women's soccer coaches felt this was the case as evidenced by their mean score of 4.61, which fell squarely between "somewhat agree" and "agree". Men's coaches felt differently in this content area as evidenced by their mean score of 3.84, which fell short of "somewhat agree" but farther away from "somewhat disagree" ( $p=.013$, HOV $p=.259)$.

\section{Track and Field}

None of the 11 questions showed significant differences between men's and women's coaches. As mentioned previously, at many universities, the head coach oversees both programs but has a top assistant coach handle the primary duties of one team. Additionally, the mean scores per questions show very little differences in responses based on gender.

\section{ANOVA}

The next step in the analysis process was to run a one-way ANOVA (alpha set at .05 for the purposes of this study) to determine differences between all six sports. The ANOVA was appropriate as it looks to analyze the difference in group means in a sample (Raymondo, 2015). In this case, the analysis was looking at differences in how the coaches of each of the six sports answered the 11 questions related to SES and recruiting practices. Unlike the independent samples t-test, the ANOVA compares the scores of each sport compared to the other five (for example baseball to softball, men's soccer, women's soccer, men's track and field, women's track and field). After running the ANOVA, Fisher's Least Significant Difference (LSD) was utilized as a post-hoc test. The LSD was most appropriate as it recognizes each category as having $\mathrm{n}$ values as different quantities and identifies which two groups differed in the analysis.

After conducting the ANOVA, evidence suggests statistically significant differences among the groups in four of the questions: 2, 5, 10, and 11.

Q2 asked all coaches whether determining a recruit's SES status was a factor in the entire recruiting process. The responses provided evidence there was a statistically significant difference $(F(5,325)=2.755, p=.019)$. 
After running the LSD, the sports that were statistically different when comparing the six sports were baseball to softball $(p=.043)$, baseball to women's soccer $(p=.024)$; softball to men's soccer ( $\mathrm{p}=.015)$; men's track and field to women's soccer ( $p=.044)$; women's track to women's soccer $(p=.027)$; men's soccer to women's soccer $(\mathrm{p}=.007)$. The mean scores for each sport (and total), as well as the standard deviations, are presented in Table 2.

Table 2

Summary of Means, and Standard Deviations by Sport

\begin{tabular}{lcc}
\hline \multicolumn{1}{c}{ Sport } & M & SD \\
\hline Baseball & 4.59 & 1.38 \\
Softball & 3.98 & 1.56 \\
Track (men) & 4.44 & 1.42 \\
Track (women) & 4.48 & 1.39 \\
Soccer (men) & 4.71 & 1.21 \\
Soccer (women) & 3.95 & 1.45 \\
Combined & 4.31 & 1.45
\end{tabular}

Q5 asked coaches if they have personal experience dealing with studentathletes dropping out of school due to financial constraints. Significant differences were found between the coaches responses $(F(5,325)=10.78$, $p=<.001)$. Baseball coaches and women's soccer coaches were significantly different in their responses $(p=.002)$. Softball coaches were also found to be significantly different than men's and women's track and field coaches $(p<.001$ for both) and significant differences were found between softball and men's soccer coaches $(p=.009)$. 
Men's and women's track and field coaches also saw statistically significant differences in their responses compared to women's soccer coaches $(p<.001$ for both). Statistically significant differences were also found between men's soccer coaches and women's soccer coaches $(p<.001)$. Clearly, women's soccer coaches were significantly different than all sports except for softball, and the baseball and softball coaches were not significantly different from one another. Each of the mean scores and standard deviations for the six sports are shown in Table 3.

Table 3

Summary of Means, and Standard Deviations by Sport

\begin{tabular}{lcc}
\hline \multicolumn{1}{c}{ Sport } & M & SD \\
\hline Baseball & 3.97 & 1.54 \\
Softball & 3.51 & 1.51 \\
Track (men) & 4.51 & 1.33 \\
Track (women) & 4.49 & 1.36 \\
Soccer (men) & 3.04 & 1.63 \\
Soccer (women) & 3.04 & 1.63 \\
Combined & 3.93 & 1.56
\end{tabular}

Q10 asked coaches how commonplace recruiting from club sports has become in their respective sports, and whether watching potential recruits in club sport competition is a large part of the recruiting process. This question saw much disparity between coaches from baseball and softball, and men's and women's soccer compared to men's and women's track and field. The F $(5,325)$ value of $79.26(\mathrm{p}<.001)$ was due to the practical application of club sports in baseball/softball and soccer, while club sport programs in track and field, while existent, are not as prominent. Baseball coaches, while scoring close to "agree" on this question, still showed statistically significant responses from all other sports as well ( $p=.026$ compared to both softball and men's soccer; $p<.001$ compared to men's and women's track and field and women's soccer. Table 4 represents the mean scores and standard deviations of each of the sports for Q10. 
Table 4

Summary of Means and Standard Deviation by Sport

\begin{tabular}{lcc}
\hline \multicolumn{1}{c}{ Sport } & M & SD \\
\hline Baseball & 4.73 & 1.76 \\
Softball & 5.36 & 1.42 \\
Track (men) & 2.36 & 1.34 \\
Track (women) & 2.51 & 1.39 \\
Soccer (men) & 5.42 & 1.33 \\
Soccer (Women) & 5.71 & .90 \\
Combined & 4.24 & 1.97
\end{tabular}

Also related to club sport competition, Q11 asked coaches whether the need to recruit from club sports is a disadvantage to those potential recruits from low SES households. As in Q10, track and field coaches "disagreed" with this question since track and field recruits likely don't utilize club sport programs to get recruited. Like in Q10, women's soccer and softball scored this question highest and fell solidly in the "somewhat agree" range, while baseball and men's soccer coaches fell at the low level of the "somewhat agree" range. Statistically significant differences were found between men's and women's track and field and all other sports $(p<.001)$, but also a significant difference was found between men's and women's soccer coaches $(p=.009)$. Table 5 represents the mean scores and standard deviations for each of the sports on Q11. 
Table 5

Summary of Means and Standard Deviation by Sport

\begin{tabular}{lcc}
\hline \multicolumn{1}{c}{ Sport } & $\mathrm{M}$ & $\mathrm{SD}$ \\
\hline Baseball & 4.19 & 1.73 \\
Softball & 4.38 & 1.64 \\
Track (men) & 2.11 & 1.21 \\
Track (women) & 2.16 & 1.21 \\
Soccer (men) & 3.84 & 1.67 \\
Soccer (women) & 4.60 & 1.40 \\
Combined & 3.48 & 1.81
\end{tabular}

\section{Discussion}

Related to the original research questions and presentation of the hypotheses statements, the responses from the coaches provide evidence to support that socioeconomic status is a factor in how coaches recruit in the six equivalency sports presented in this study (baseball, softball, men's and women's soccer, men's and women's track and field). The data show that socioeconomic status can be a determinant in whether a potential student-athlete is even included in the recruiting process at the onset, and is a certainly a factor in the ongoing process of recruiting when determinations are made as to what percentage of scholarship can be offered in order for the recruit to "make up" the difference. Many of the coaches included in the study agreed that the search for additional funding sources, and the need to work with their school's compliance and financial aid departments is a necessity at the onset of the recruiting process. Returning to the original research questions and hypotheses statements, the decision to reject the null hypothesis statement is correct based on the responses from the coaches providing evidence that SES is, and can be, a deciding factor in whether a student-athlete is recruited at all.

The mean scores for each of the 11 content-related questions show that the coaches feel much the same way regardless of the sport and gender and are at nearly the same level of accord (with the exceptions listed related to club sports and track and field). 
Coaches of men's sports feel the need to conduct thorough diligence on a recruit's socioeconomic status at an even more robust level as indicated in the response comparisons as the men's sports have reduced scholarships available when compared to the same women's sports. Additionally, in four-of-the-six sports studied, the ability to be involved in some type of club sport activity outside the high school sponsored season is a primary recruiting tool that coaches feel can restrict potential recruits from lower socioeconomic households.

Collegiate coaches and administrators, as well as high school coaches promoting their student-athletes for college scholarships, can utilize the findings to help learn more about other funding opportunities that may be available, including those related to academic standing and community service. High school guidance counselors or those high school personnel involved with helping in the college selection process, should also be aware of how collegiate coaches in these sports mold the recruiting process. Through the data collected in this study, collegiate coaches and athletic administrators scour all opportunities for funding in order to help stack or build a scholarship offer. The recruit's ability to "pay" or make up the difference is a significant factor, and coaches and administrators can play a key role in helping determine how much money the recruit would need access to in order to accept the scholarship offered. Administrators and coaches in the collegiate athletics industry should find the information applicable, especially during heightened periods where inclusion and equality are heavily promoted. Based on the coaches' responses in this study, the ability to be recruited, at least at levels found in this study, are based on that recruit's SES.

\section{Areas of Future Research}

Areas of future research by the authors is already underway to determine the debt burden college baseball student-athletes at the NCAA Division I FBS level are taking on during their collegiate career. Since baseball is among the equivalency sports with the largest variance between average roster size and number of scholarships, an argument can be made to investigate it to provide a foundation. Once the average level of debt burden is uncovered related to the student-athlete's SES, information can be presented to argue for a scholarship increase in the sport.

With the variation in the numbers of responses per sport, conducting a study of an individual sport may provide more specific information related to recruiting and SES. This could lead to increased knowledge of how significant SES is to the recruiting process for that sport. Collecting a sample by sport of current student-athlete SES information could also provide evidence to further support the responses obtained in this study. By pursuing a study in one specific sport, researchers could likely address those recurring issues related to recruiting 
and socioeconomic status that coaches in a specific sport bring to light. Additionally, by capturing information from coaches on an individual sport basis, suggestions for improved recruiting practices may be uncovered that may assist recruits from low SES households.

From there, additional studies may be conducted that could uncover whether equivalency sport student-athletes are presented with information as to the amount of debt they may incur if they choose to accept the offer the coach/university makes. This could be part of an overall study that looks at additional funding sources for those student-athletes receiving equivalency scholarships, and how the remaining costs associated with tuition, books, and housing are offset. Most low SES households cannot make up the additional costs without grants, loans, or other types of assistance.

Future studies are also underway by the authors to determine if it may be an appropriate time to explore a reallocation of FBS football scholarship (currently at 85 full scholarships) in order to take already existing men's scholarships and spread them out over equivalency sports.

\section{Conclusion}

This is the first study specifically covering the content area of how much a potential recruit's SES factors in the recruiting process. More specifically, capturing input from coaches who are directly involved in the recruiting process provided evidence to show that a recruit's SES status is a definite factor. While this study only captured data from coaches in the six sports presented here, future studies could look at all equivalency sports to try and gain an understanding if there are differences in other sports that did not get captured in this study. This could have been due to the mainstream nature of these sports, and did not include more specific "niche" type sports such as wrestling, lacrosse, hockey, gymnastics, swimming, et al. The researchers felt, for the purposes of this study, the mainstream equivalency sports that are present in the vast majority of NCAA Division I athletic departments was an acceptable starting point.

More information about the financial ramifications of equivalency scholarships and how the "uncovered" costs can be paid for may be of great value to high school coaches, counselors, parents, and guardians as they assist studentathletes through the decision making process. 


\section{References}

Bailey, M.J. \& Dynarski, S. M., (2011). Inequality in postsecondary attainment. In Duncan, G. and Murmane, R., eds. Wither opportunity: Rising inequality schools, and children's life chances, pp. 117-132. New York: Russell Sage Foundation

Carnevale, A.P., Smith, N. and Stohl, J. (2010). Help wanted: Projections of jobs and education requirements through 2018. Georgetown University Center on Education and the Workforce.

Eime, R. M., Charity, M. J., Harvey, J.T. \& Payne, W.R. (2015). Participation in sport and physical activity: Associations with socioeconomic status and geographical remoteness. BMC Public Health.

Gieser, J.D. (2012). Financial aid through a Bourdieu-ian lens: Inequality perpetuated or an opportunity for change? (cover story). Journal of College Admissions. (216). 8-14

Haskins, R., Holzer, H., \& Lerman, R. (2009, May). Promoting economic mobility by increasing postsecondary education. Economic Mobility Project, Pew Charitable Trusts, pp. 43-44

Huffman, L.T. \& Cooper, C.G. (2012). I'm taking my talents to.. an examination of hometown socio-economic status on the college-choice factors of football student-athletes at a southeastern university. Journal of Issues in Intercollegiate Athletics, 5, 225-246

Isaacs, J.B., Sawhill, I. \& Haskins, R. (2008). Getting ahead or losing ground: Economic mobility in America. Washington, D.C.: Brookings Institution

Ma, J., Pender, M., \& Welch, M. (2016). Education pays 2016: The benefits of higher education for individuals and society. Trends in Higher Education Series. College Board.

Moore, J. (2017). Do you have to play club sports to get recruited? Retrieved from https://usatodayhss.com/2017/do-you-have-to-play-club-sports-toget-recruited

National Collegiate Athletic Association. (2019). 2019-20 NCAA Division I Manual. http://www.ncaapublications.com/productdownloads/D120.pdf.

Oreopoulis, P. \& Salvanes, K.G. (2011). Priceless: The nonpecuniary benefits of schooling. Journal of Economic Perspectives, 25 (1): 159-84.

Post, E. G., Green, N.E., Schaefer, D.A., Trigsted, S.M., Brooks, M.A., Mcguine,T.A., . . . Bell, D.R. (2018). Socioeconomic status of parents with children participating on youth club sport teams. Physical Therapy in Sport, 32, 126-132.

Raymondo, J.C. (2015). Statistical analysis in the behavioral sciences. Dubuque, IA: Kendall Hunt. 
Ross, C. E., \&Wu, C. (1995). The links between education and health. American Sociological Review, 60, 719-745.

Smith, J. (2017). Paying to play: How much do club sports cost? Retrieved from https://usatodayhss.com/2017/paying-to-play-how-much-do-club-sportscost

Smith, J. I., Pender, M., \& Howell, J.S. (2013). The full extent of academic undermatch. Economics of Education Review, 32: 247-261

Terenzini, P.T., Cabrera, A.F., \& Bernal, E.M. (2001). Swimming against the tide: The poor in American higher education. College Entrance Examination Board, New York, NY.

United States. Executive Office of the President, issuing body. (2014). Increasing college opportunity for low-income students: Promising models and a call to action / The Executive Office of the President.

U.S. Department of Education. (n.d.). College affordability and completion: Ensuring a pathway to completion. Retrieved from https://www.ed.gov/college

U.S. Department of Education, National Center for Education Statistics. (2017).

Table 330.20: Average undergraduate tuition and fees and room and board rates charged for full-time students in degree-granting postsecondary institutions, by control and level of institution and state or jurisdiction: 2015-16 and 2016-17. In U.S. Department of Education, National Center for Educational Statistics, Digest of Education Statistics (2017 ed.). Retrieved from https://nces.ed.gov/programs/digest/d17/tables/dt17_330.20.asp?current=y es

Walpole, M. (2003). Socioeconomic status and college: How SES affects college experiences and outcomes. The Review of Higher Education: Journal of the Association of Higher Education, 27(1): 45-73 